\title{
Rancang Bangun Aplikasi Media Promosi Pariwisata dan Kebudayaan Kabupaten Kuningan Berbasis Web
}

\author{
Tito Sugiharto, S.Kom., M.Eng \\ Program Studi Teknik Informatika S1 \\ Fakultas Ilmu Komputer Universitas Kuningan \\ Kuningan Jawa Barat, Indonesia \\ tito@uniku.ac.id
}

\begin{abstract}
This research was made with the goal of producing an app to promote tourism and culture in Kuningan Regency based web. The problem in this research is the need to build a web based application media campaign to increase the number of tourists visiting the Kuningan Regency. The research objective to be achieved is the application of media promotion of tourism and culture that attract web based and can accessed using the Internet. With the application of promotional media is expected to increase the number of tourists visiting the Kuningan Regency. This study will discuss how to design and develop application Kuningan Regency tourism and culture based web. With this application, the tourists can get information about the existence of diversity of tourism in the Kuningan Regency. In the process of making this application used the methodology of system design and cultural tourism application is built using the PHP programming language and MySQL database. These applications can be run via a browser connected to the Internet.
\end{abstract}

Keywords- tourism; promotion; Kuningan; applications; Internet.

\section{PENDAHULUAN}

Pariwisata telah menjadi sebuah industri yang dapat memberikan pemasukan yang sangat besar. Pada saat ini industri pariwisata telah berkembang sangat pesat, dan didukung dengan kemajuan teknologi informasi. Berbagai jenis ragam pariwisata di promosikan oleh masing-masing daerah untuk menarik para wisatawan datang berkunjung. Salah satu daerah yang selalu giat mempromosikan ragam pariwisatanya adalah Kabupaten Kuningan.

Kabupaten Kuningan merupakan salah satu Kabupaten yang ada di wilayah Jawa Barat, berbatasan langsung dengan Cirebon, Brebes, dan Majalengka. Ragam pariwisata yang terdapat di Kabupaten Kuningan sangatlah banyak, diantaranya adalah wisata air, wisata pegunungan, wisata kuliner, wisata rohani dan masih banyak lagi.

Dalam mempromosikan ragam wisata yang ada di Kabupaten Kuningan Dinas Pariwisata dan Kebudayaan Kabupaten Kuningan masih menggunakan media brosur. Media brosur disebar oleh pekerja Dinas Pariwisata dan
Kebudayaan Kuningan ke berbagai daerah untuk mendatangkan wisatawan yang berkunjung.

Penggunaan media brosur sebagai media promosi ragam wisata yang ada di Kabupaten Kuningan dirasakan belum maksimal untuk meningkatkan jumlah wisatawan yang datang ke Kabupaten Kuningan. Media brosur masih memiliki keterbatasan dalam hal penyebaran informasi, penjelasan tentang ragam wisata, dan keterbatasan penyebaran brosur.

Diperlukan sebuah media promosi yang dapat dengan mudah digunakan dan diakses oleh wisatawan yang ingin mencari informasi tentang ragam wisata di Kabupaten Kuningan.

Secara umum rumusan permasalahan yang terdapat pada Rancang Bangun Aplikasi Media Promosi Pariwisata dan Kebudayaan Kabupaten Kuningan Berbasis Web adalah sebagai berikut.

1. Belum terdapatnya suatu aplikasi media promosi berbasis Web yang dapat membantu meningkatkan promosi ragam wisata di Kabupaten Kuningan.

2. Bagaimana cara merancang dan membangun aplikasi media promosi berbasis web menggunakan PHP dan MySQL.

Pada paper ini dibahas mengenai bagaimana merancang aplikasi media promosi Pariwisata dan kebudayaan berbasis web. Dengan adanya aplikasi ini diharapkan dapat membantu Dinas Pariwisata dan Kebudayaan Kabupaten Kuningan untuk meningkatkan jumlah wisatawan yang datang berkunjung ke Kabupaten Kuningan.

Penelitian terkait dengan pariwisata telah dilakukan oleh peneliti-peneliti sebelumnya. Ganjar melakukan kajian dan penelitian mengenai bagaiamana membuat website pariwisata pantai khususnya di Yogyakarta dengan context awareness. Website yang dapat diakses dengan segala resolusi device yang tampilannya dapat menyesuaikan device tersebut. Dalam penelitiannya diterapkan konsep context-aware seperti memasukan data update dari check-in foursquare akan memberikan rekomendasi kepada pengguna untuk memilih lokasi pantai[1]. 
Penelitian tentang pariwisata juga telah dilakukan oleh ahmad. Dari hasil penelitian tersebut dapat disimpulkan bahwa dengan dibangunnya aplikasi navigasi pariwisata berbasis web dapat memudahkan pengguna dalam memperoleh informasi mengenai tempat wisata di kota Palopo secara lngkap dan detail[5].

Penelitian tentang pariwisata lainnya juga telah dilakukan oleh mailany. Dalam penelitiannya dibahas mengenai pembuatan Aplikasi Sistem Informasi Geografis pariwisata kota Kupang. Dari hasil penelitian tersebut dapat disimpulkan bahwa Aplikasi Sistem Informasi Geografis dapat membantu para wisatawan dalam mendapatkan informasi mengenai pariwisata yang ada di kota Kupang [2].

Mengacu pada hasil penelitian sebelumnya terkait dengan pembuatan aplikasi pendukug promosi pariwisata, belum terdapat suatu aplikasi promosi pariwisata berbasis web untuk kota Kuningan. Dengan demikian, diharapkan dari hasil penelitian ini dapat memberikan informasi yang lebih jelas dan banyak tentang ragam pariwisata yang ada di Kabupaten Kuningan untuk para wisatawan.

\section{TINJAUAN PUSTAKA}

Pariwisata merupakan istilah atau kata yng diberikan apabila seseorang wisatawan melakukan perjalanan itu sendiri, atau dengan kata lain kegiatan dan kejadian yang terjadi ketika seseorang pengunjung melakukan suatu perjalanan.

Ada beberapa jenis pariwisata yang sudah dikenal, antara lain: [3]

1. Wisata Budaya, yaitu perjalanan yang dilakukan atas dasar keinginan untuk memperluas pandangan hidup seseorang dengan cara mengadakan kunjungan ke tempat lain atau ke luar negeri, mempelajari keadaan rakyat, kebiasaan dan adat istiadat mereka, cara hidup mereka, kebudayaan dan seni mereka.

2. Wisata Olahraga, yaitu wisatawan-wisatawan yang melakukan perjalanan dengan tujuan berolahraga.

3. Wisata Kesehatan, yaitu perjalanan seseorang wisatawan dengan tujuan untuk menukar keadaan dan lingkungan tempat sehari-hari di mana ia tinggal demi kepentingan beristirahat baginya dalam arti jasmani dan rohani.

4. Wisata Bahari, yaitu wisata yang banyak dikaitkan dengan danau, pantai.

5. Wisata industri, yaitu perjalanan yang dilakukan oleh rombongan pelajar atau mahasiswa, atau orang-orang awam ke suatu kompleks atau daerah perindustrian, dengan maksud dan tujuan untuk mengadakan penelitian.

6. Wisata komersial, yaitu termasuk perjalanan untuk mengunjungi pameranpameran dan pecan raya yang bersifat komersial, seperti pameran industri, dan pameran dagang.

7. Wisata Cagar Alam, yaitu jenis wisata yang biasanya diselenggarakan oleh agen atau biro perjalanan yang mengkhususkan usaha-usaha dengan mengatur wisata ke tempat atau daerah cagar alam, taman lindung, hutan daerah pegunungan dan sebagainya.
Kebudayaan adalah hasil karya manusia dalam usahanya mempertahankan hidup, mengembangkan keturunan, dan meningkatkan taraf kesejahteraan dengan segala keterbatasan kelengkapan jasmaninya serta sumber-sumber alam yang ada disekitarnya.

Dinas pariwisata dan Kebudayaan Kabupaten Kuningan merupakan salah satu Instansi Pemerintah dimana bertanggung jawab pada tempat pariwisata dan kebudayaan yang ada di Kabupaten Kuningan. Dinas pariwisata dan kebudayaan yang dibentuk berdasarkan Peraturan Daerah Nomor 11 tahun 2008 tentang Dinas Daerah dan Surat Keputusan Bupati No. 42 tahun 2008 tentang Tugas Pokok Fungsi dan Uraian Tugas Dinas Pariwisata dan Kebudayaan.

Ragam Obyek wisata yang ada di Kabupaten Kuningan, diantaranya adalah: Linggarjati Indah, Kolam Renang Sanggariang, Tirta Agung Mas, Sangkan Resort Aqua Park, The Mountain Recreation Park, Curug Putri, Talaga Remis, Kolam Ikan Cigugur, Pemandian Sangkanhurip, Taman Purbakala Cipari, Waduk Darma, Balong Keramat Darmaloka, Gedung Perundingan Linggarjati, Kolam Ikan dan Sumur 7 Cibulan.

Sementara itu untuk ragam seni budaya yang ada di Kabupaten Kuningan, diantaranya adalah: Seren Taun, Gong Renteng, Tari Buyung, Sintren, Cingcowong, Sapton, Pesta Dadung dan kawin Cai.

Perancangan merupakan suatu tahapan yang digunakan untuk menggambarkan, merencanakan dan dan membuat suatu aplikasi. Perancangan adalah spesifikasi umum dan terperinci dari pemecahan masalah berbasis komputer yang telah dipilih selama tahap analisis [4].

Perancangan dimulai dengan menentukan semua kebutuhan yang akan memenuhi apa yang dibutuhkan oleh sistem, siapa aktor yang dapat berperan, dan bagaimana menyelesaikan seluruh rancangannya. Pada umumnya, perancangan selalu diawali mulai dari proses input dan berakhir menuju ke proses output[6].

Metode perancangan sistem yang digunakan dalam merancang aplikasi media promosi pariwisata dan kebudayan ini adalah menggunakan metode RUP (Rational Unified Process). RUP merupakan suatu metode rekayasa perangkat lunak yang dikembangkan dengan mengumpulkan berbagai best practices yang terdapat dalam industri pengembangan perangkat lunak.

Dalam pengembangan perangkat lunak metode RUP lebih fokus pada aktifitas menciptakan dan merawat model daripada aktifitas produksi yang memfokuskan pada pembuatan dokumen project yang banyak. Metode RUP memiliki 4 fase, yaitu: fase inception, fase elaboration, fase construction, fase transition.

Dalam merancang suatu aplikasi perangkat lunak dibutuhkan suatu model untuk memahami permasalahan, untuk menggambarkan suatu proses bisnis yang sedang berjalan, dan menghubungkan dengan pihak-pihak yang terlibat.

Salah satu notasi standar pemodelan yang dapat digunakan adalah Unified Modeling Language (UML). UML adalah sebuah pemodelan yang berdasarkan grafik atau gambar untuk 
memvisualisasi, menspesifikasikan, membangun dan memdokumentasikan sebuah sisitem pengembangan perangkat lunak berbasis objek.

UML menyediakan beberapa notasi dan artifact standar yang bisa digunakan sebagai alat komunikasi bagi pembuat dalam proses analisis dan desain. Artifact didalam UML didefinisikan sebagai informasi dalam bentuk yang dihasilkan dalam proses pengembangan perangkat. Untuk membuat suatu model, UML memiliki diagram grafis sebagai berikut: use case diagram, activity diagram, class diagram, sequence diagram.

\section{METODE PENELITIAN}

Metode RUP memiliki 4 fase, yaitu: fase inception, fase elaboration, fase construction, fase transition. Fase inception adalah tahapan awal atau biasa disebut juga dengan tahapan persiapan. Fase inception fokus pada penentuan manfaat aplikasi perangkat lunak yang harus dibangun. Fase inception memiliki tujuan untuk menentukan ruang lingkup suatu sistem aplikasi. Fase inception juga menentukan bentuk business modelling dan analisis dari aplikasi yang akan dirancang dan mennetukan requirement.

Business modelling dibuat untuk menggambarkan alur dari sistem yang sedang berjalan dan dari sistem usulan yang akan dirancang. Sistem promosi yang ada saat ini masih sangat konvensional yaitu dengan memberikan brosur pariwisata yang berisi informasi tempat dan ragam wisata yang ada di Kabupaten Kuningan.

Pada fase inception dilakukan juga analisis kebutuhan masukan. Dari analisis kebutuhan masukan diperlukan dua macam data, yaitu : data spasial dan data atribut. Data spasial merupakan data yang erupa data nama-nama tempat wisata dan kebudayaan yang ada di Kabupaten Kuningan. Data atribut merupakan data yang berupa informasi yang menjelaskan isi dari data spasial tersebut.

Dalam fase inception ditentukan juga requirement atau kebutuhan. Kebutuhan ini dikelompokan menjadi dua bagian, yaitu: kebutuhan fungsional dan kebutuhan non-fungsional. Adapun kebutuhan fungsional dalam aplikasi media promosi pariwisata dan kebudayaan ini adalah sebagai berikut:

1. Aplikasi ini harus bisa diakses menggunakan web browser.

2. Aplikasi ini harus bisa menampilkan informasi ragam wisata dan kebudayaan di Kabupaten Kuningan.

3. Aplikasi ini harus bisa menampilkan informasi kegiatan yang ada di Dinas Pariwisata dan kebudayaan Kabupaten Kuningan.

Kebutuhan non-fungsional dalam aplikasi ini ada dua, yaitu kebutuhan perangkat keras dan kebutuhan perangkat lunak. Perangkat keras yang digunakan dalam proses pembuatan aplikasi ini dapat dilihat pada Tabel 1.
TABel 1. PerangKat Keras

\begin{tabular}{|l|l|}
\hline \multicolumn{1}{|c|}{ Perangkat Keras } & \multicolumn{1}{c|}{ Keterangan } \\
\hline Notebook & ASUS I3-370M \\
\hline Memory & $2 \mathrm{~GB}$ \\
\hline VGA & Nividia GeForce 310 VRAM \\
\hline Hardisk & $320 \mathrm{~GB}$ \\
\hline
\end{tabular}

Perangkat lunak yang dibutuhkan dalam proses pembuatan aplikasi ini dapat dilihat pada Tabel 2.

TABel 2. PeRAngKat LunAK

\begin{tabular}{|l|l|}
\hline \multicolumn{1}{|c|}{ Perangkat Lunak } & \multicolumn{1}{c|}{ Keterangan } \\
\hline Sistem Operasi & Windows 7 \\
\cline { 2 - 2 } Database & MySQL \\
\hline Bahasa Pemrograman & PHP \\
\hline Aplikasi Pendukung & Dreamweaver \\
\hline Browser & Moziila Firefox, Google Chrome \\
\hline
\end{tabular}

Setelah fase inception dilanjutkan ke fase elaboration. Fase elaboration digunakan untuk menentukan use case dari aplikasi yang dibangun. Tahap ini memandang sistem lebih dalam, menganalisa masalah utama yang sedang dikembangkan, dan mulai mempersiapkan tahapan selanjutnya yaitu tahapan construction.

Use case diagram mendeskripsikan aplikasi, lingkungan dan relasi antara aplikasi dengan lingkungannya. Gambar 1 merupakan gambaran use case diagram dari aplikasi.

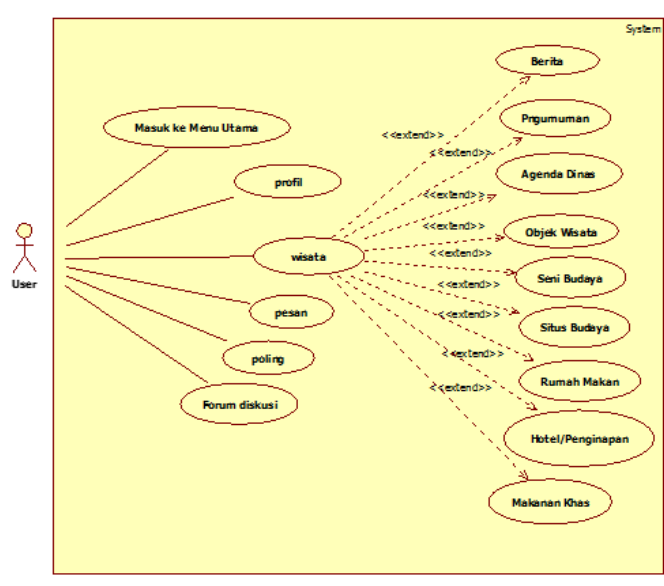

Gambar 1. Use Case Diagram Aplikasi

Pada gambar 1 user dapat mengakses ke menu utama, profil, wisata, pesan, polling dan forum diskusi. Di dalam menu wisata terdapat sub menu berita, pengumuman, agenda dinas, obyek wisata, seni budaya, situs budaya, rumah makan, hotel dan makanan khas.

Setelah dibuat use case diagram langkah berikutnya adalah membuat activity diagram. activity diagram digunakan untuk 
menggambarkan suatu rangkaian aliran dari kegiatan yang berhubungan dengan sistem.

Gambar 2 merupakan gambaran activity diagram user pada saat mengakses halaman situs. User dapat mengakses situs kemudian sistem akan menampilkan halaman utama di browser. Selanjutnya user dapat memilih fitur wisata kemudian sistem akan menampilkan halaman data wisata.

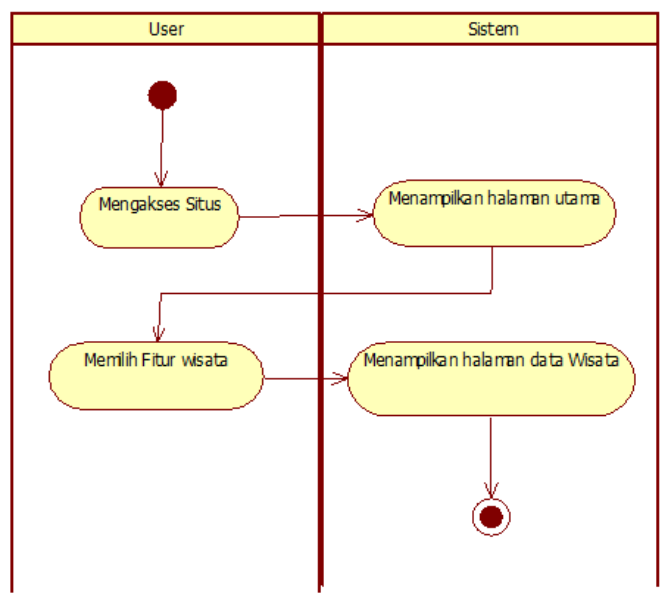

Gambar 2. Activity Diagram User

Setelah membuat activity diagram langkah berikutnya adalah membuat sequence diagram. Gambar 3 menggambarkan sequence diagram User melihat data wisata.

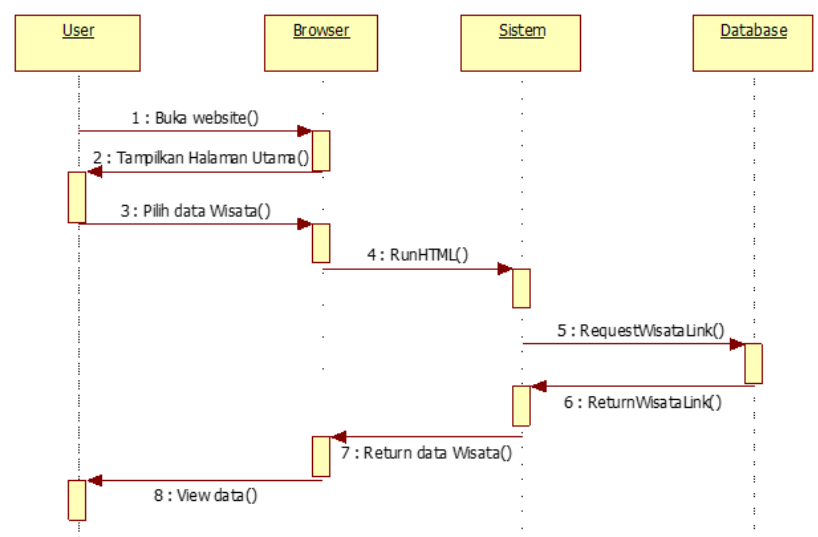

Gambar 3. Sequence Diagram User

Pada gambar 3 menggambarkan tentang Sequence Diagram User, dimana seorang user akan membuka sebuah website kemudian pada halaman browser akan ditampilkan halaman utama. Setelah itu user dapat memilih data wisata yang ada pada browser, kemudian browser akan menjalankan script HTML dan mengmabil data dari database kemudian akan ditampilkan kembali ke user.
Setelah membuat Sequence Diagram langkah selanjutnya adalah membuat perancangan antarmuka. Perancangan antarmuka bertujuan untuk memberikan gambaran tentang aplikasi yang akan dibangun sehingga akan mempermudah dalam mengimplementasikan serta akan memudahkan dalam pembuatan aplikasi yang bersifat dinamis dan menarik untuk digunakan oleh user. Gambar 4 merupakan rancangan antarmuka halaman utama untuk aplikasi media promosi pariwisata dan kebudayaan Kabupaten Kuningan.

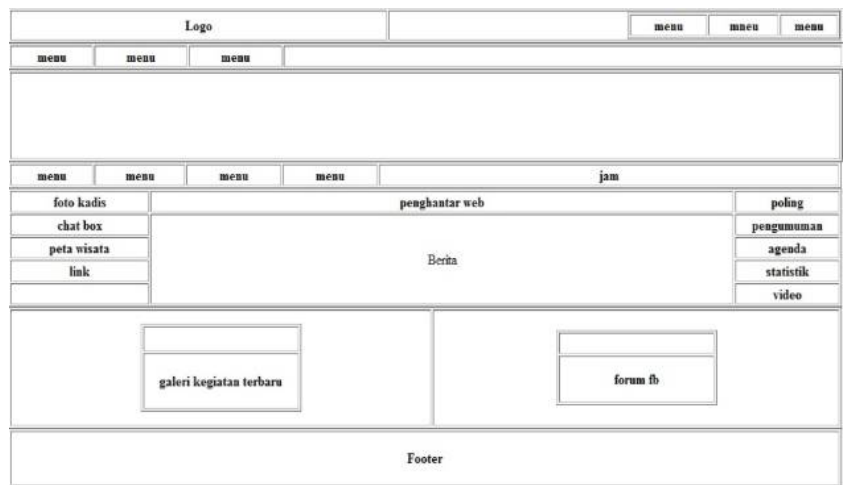

Gambar 4. Rancangan Halaman Utama

\section{HASIL DAN PEMBAHASAN}

Langkah selanjutnya setelah melewati tahapan Inception dan Elaboration adalah mengerjakan tahapan Contruction dan Transition. Tahapan Contruction mengerjakan proses pembuatan aplikasi mulai dari desain tampilan dan pembuatan kode program. Pada tahapan ini juga diperhatikan tentang menu-menu yang ada di aplikasi harus sesuai dengan rancangan antarmuka yang dibuat.

Gambar 5 merupakan hasil tampilan menu utama aplikasi media promosi pariwisata dan kebudayaan kabupaten Kuningan berbasis web. Tampilan halaman utama sudah sesuai dengan rancangan antarmuka halaman utama.

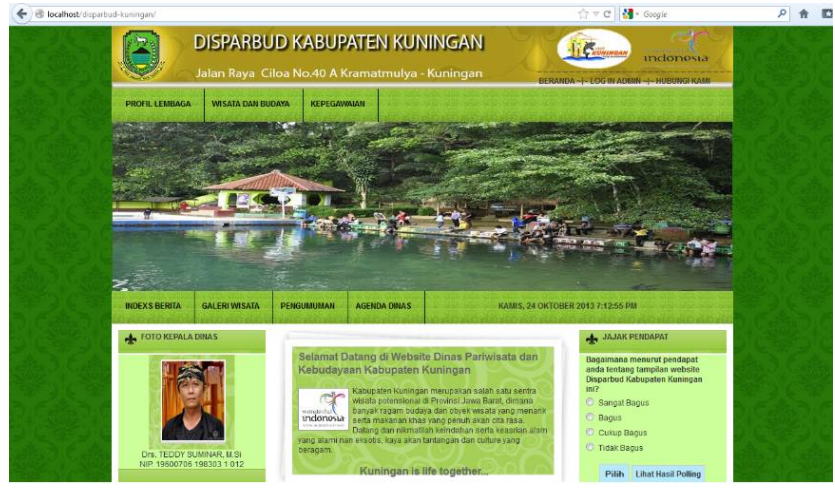

Gambar 5. Tampilan Halaman Utama 
Gambar 6 merupakan tampilan untuk halaman login admin. Halaman login admin digunakan oleh admin untuk masu ke halaman utama admin. Pada halaman login admin ini, untuk masuk ke halaman utama admin dibutuhkan username dan password yang benar untuk login.

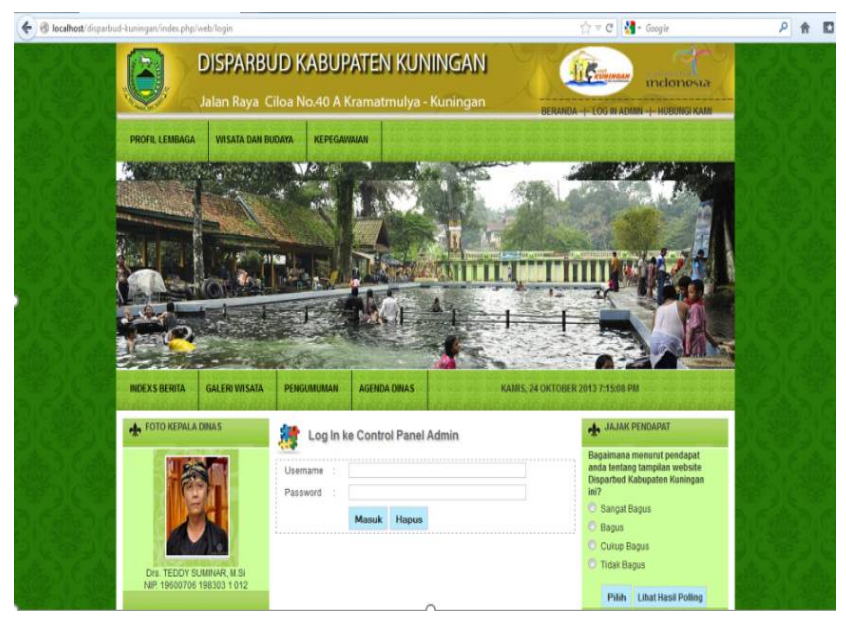

Gambar 6. Tampilan Halaman Login Admin

Setelah admin memasukan username dan password yang benar maka admin dapat masuk ke halaman utama admin. Gambar7 merupakan halaman menu utama admin.

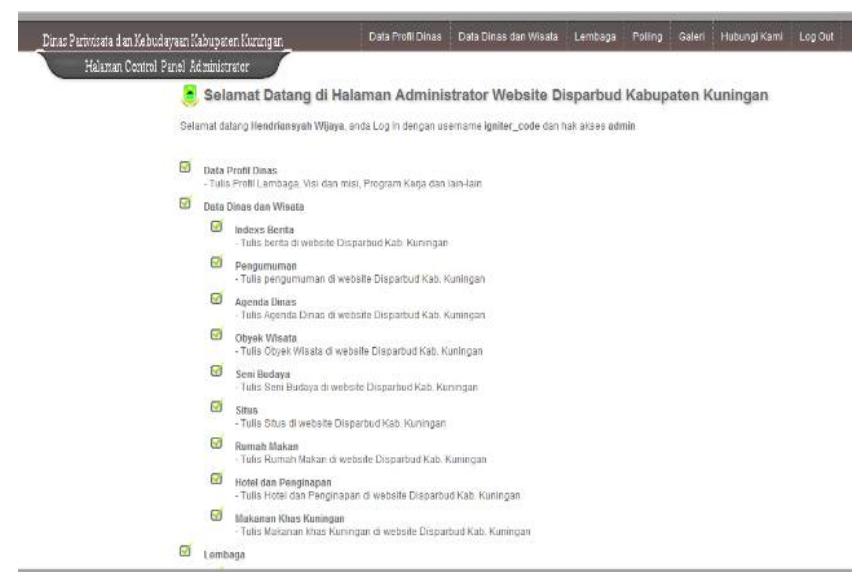

Gambar 7. Tampilan Halaman Utama Admin

Gambar 8 merupakan tampilan halaman seni dan budaya. Halaman seni dan budaya adalah halaman yang akan ditampilkan ketika pengunjung memilih menu wisata dan budaya. Pada halaman ini pengunjung dapat melihar ragam dan jenis dari wisata dan budaya yang ada di Kabupaten Kuningan.

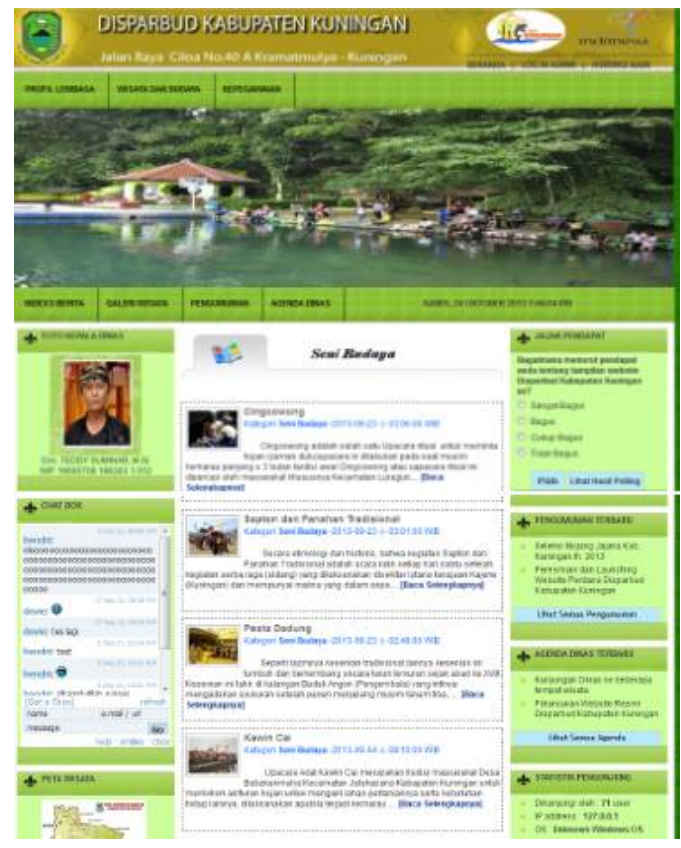

Gambar 8. Tampilan Halaman Seni dan Budaya

Tahapan terakhir pada fase RUP adalah tahapan transition. Tahap transition merupakan tahapan yang fokus pada proses pengujian aplikasi perangkat lunak dan memperbaiki masalahmasalah yang muncul pada saat dan setelah pengujian.

Proses pengujian aplikasi perangkat lunak memiliki banyak cara. Salah satu bentuk pengujian aplikasi perangkat lunak dapat menggunakan pengujian Black Box. Pengujian Black Box merupakan cara pengujian aplikasi perangkat lunak yang berfokus pada spesifikasi fungsional dari aplikasi perangkat lunak yang dibangun.

Adapun hasil pengujian Black Box yang telah dilakukan dapat dilihat pada Tabel 3 .

TABel 3. Hasil PENGUJiAn BLACK BOX

\begin{tabular}{|c|c|c|c|c|}
\hline No & $\begin{array}{c}\text { Fungsi } \\
\text { yang di } \\
\text { uji }\end{array}$ & Cara Menguji & $\begin{array}{c}\text { Hasil yang } \\
\text { diharapkan }\end{array}$ & $\begin{array}{c}\text { Hasil } \\
\text { yang } \\
\text { keluar }\end{array}$ \\
\hline 1 & $\begin{array}{c}\text { Cek } \\
\text { Login } \\
\text { Admin }\end{array}$ & $\begin{array}{c}\text { Admin } \\
\text { memasukan } \\
\text { username dan } \\
\text { password }\end{array}$ & $\begin{array}{c}\text { Admin dapat } \\
\text { masuk } \\
\text { kedalam } \\
\text { menu utama }\end{array}$ & Valid \\
\hline 2 & $\begin{array}{c}\text { Tambah } \\
\text { Data } \\
\text { Wisata }\end{array}$ & $\begin{array}{c}\text { Menambahkan } \\
\text { data wisata } \\
\text { oleh admin. }\end{array}$ & $\begin{array}{c}\text { Program } \\
\text { dapat } \\
\text { menambahkan } \\
\text { data wisata }\end{array}$ & Valid \\
\hline 3 & $\begin{array}{c}\text { Cek } \\
\text { Menu } \\
\text { Wisata }\end{array}$ & $\begin{array}{c}\text { User mengklik } \\
\text { menu wisata }\end{array}$ & $\begin{array}{c}\text { Dapat melihat } \\
\text { isi dari menu } \\
\text { wisata }\end{array}$ & Valid \\
\hline 4 & $\begin{array}{c}\text { Cek } \\
\text { Chatbox }\end{array}$ & $\begin{array}{c}\text { User } \\
\text { mengetikan }\end{array}$ & $\begin{array}{c}\text { User dapat } \\
\text { menuliskan }\end{array}$ & Valid \\
\hline \multicolumn{4}{|c}{} \\
\hline
\end{tabular}




\begin{tabular}{|c|c|c|c|c|}
\hline & $\begin{array}{c}\text { pesan pada } \\
\text { chatbox }\end{array}$ & $\begin{array}{c}\text { pesan ke } \\
\text { dalam } \\
\text { chatbox }\end{array}$ & \\
\hline 5 & $\begin{array}{c}\text { Cek } \\
\text { Galeri } \\
\text { Kegiatan }\end{array}$ & $\begin{array}{c}\text { User mengklik } \\
\text { menu galeri } \\
\text { kegiatan }\end{array}$ & $\begin{array}{c}\text { User dapat } \\
\text { melihat isi } \\
\text { dari galeri } \\
\text { kegiatan }\end{array}$ & valis \\
\end{tabular}

Dari hasil pengujian Black Box pada program aplikasi yang dibuat telah dihasilkan pengujian yang valid. Semua tahapan pengujian Black Box menghasilkan keluaran yang valid.

\section{KESIMPULAN DAN SARAN}

Aplikasi media promosi pariwisata dan kebudayaan Kabupaten Kuningan berbasis web dibuat dengan menggunakan metode RUP dan bahasa pemrograman PHP. Berdasarkan hasil implementasi dan pembahasan yang dilakukan, maka dapat ditarik kesimpulan sebagai berikut:

1. Dengan adanya aplikasi media promosi pariwisata dan kebudayaan Kabupaten Kuningan ini dapat dijadikan sebagai media promosi tambahan yang dapat diakses dengan mudah oleh setiap orang.

2. Dengan adanya aplikasi media promosi pariwisata dan kebudayaan Kabupaten Kuningan ini dapat membantu parawisatawan dalam hal mencari informasi tentang ragam wisata dan budaya yang ada di Kabupaten Kuningan.

3. Dengan adanya aplikasi media promosi pariwisata dan kebudayaan ini dapat membantu wisatawan untuk mengetahui cara berkunjung ke Kabupaten Kuningan ini.

Saran dari hasil pembuatan aplikasi media promosi pariwisata dan kebudayaan Kabupaten Kuningan berbasis web ini adalah:

1. Dibutuhkan kerjasama dengan berbagai pihak atau tokoh masyarakat yang ada di Kabupaten Kuningan untuk pendataan lebih lanjut mengenai ragam wisata dan kebudayaan yang ada di Kabupaten Kuningan.

2. Perlu ditambahan menu untuk pencarian rute terpendek menuju lokasi wisata dan kebudayaan yang ada di Kabupaten Kuningan.

\section{DAFTAR PUSTAKA}

[1] Ganjar Widiatmansyah, R. F. (2015). Desain Responsive Website Pariwisata Dengan ContextAware. Seminar Nasional Teknologi Informasi dan Multimedia (pp. 4.7-25). 2015: STMIK AMIKOM Yogyakarta.

[2] Mailany Tumimomor, E. J. (2013). SISTEM INFORMASI GEOGRAFIS. Jurnal Nasional Pendidikan Teknik Informatika (JANAPATI), 142.
[3] Pendit, S. (2002). Ilmu Pariwisata. Jakarta: PT Prandnya Paramita.

[4] Susanto, A. (2004). Sistem Informasi Akuntansi Konsep dan Pengembangan Berbasis Komputer. bandung: Lingga Jaya.

[5] Syahrir, A. S. (2016). SISTEM INFORMASI NAVIGASI PARIWISATA BERBASIS WEB DAN ANDROID PADA DINAS KEBUDAYAAN PARIWISATA KOTA PALOPO. Seminar Nasional Teknologi Informasi dan Multimedia (pp. 4.7-1). Yogyakarta: STMIK AMIKOM Yogyakarta.

[6] Tito Sugiharto, P. N. (2016). Rancang Bangun Aplikasi Mobile Pariwisata Berbasis J2ME Menggunakan Metode Rational Unified Process. Seminar Nasional Teknologi Informasi dan Multimedia 2016 (pp. 4.7-19). Yogyakarta: STMIK AMIKOM Yogyakarta. 